\section{Hunger and public policy}

In the mid-1970s, hunger in this country fell to an all-time low, largely due to the Great Society initiatives of the 1960 s. Since then, cutbacks in food, job and housing programs, coupled with a long-term decline in workers' real wages, have spurred hunger rates. With the recent recession, the situation worsened further. Tufts University's Center on Hunger, Poverty and Nutrition Policy estimated that 30 million Americans were hungry in 1991 - a $54 \%$ increase since 1984 .

Responding to the visible signs of hunger in their communities, private citizens have established close to 150,000 food pantries and soup kitchens nationwide - most of them since 1980. Today more than half of Americans contribute to hunger relief, distributing as much as $\$ 4$ billion of food annually.

But the private feeding movement has not been able to close the gap left by federal cutbacks. Why? Because the size and efficiency of federal food programs dwarfs even the extraordinary efforts of private citizens. After the cutbacks of the 1980 s, federal food programs still provide $\$ 39$ billion to the needy -10 times the amount private charities have mustered.

"The private feeding movement can provide part of the solution to hunger, but it is neither possible nor appropriate for private charities to take the place of government programs," said Mary Fujii, UC home economist in Contra Costa County. "Soup kitchens and food pantries must depend on donated food, and supplies vary according to the wealth of communities. Even well-stocked facilities sometimes run out of food and turn people away. Charities cannot offer consistent supplies of staple foods, much less food that is nutritionally balanced. Donated food is least plentiful in the neediest places."

While federal food programs are assisting more people than ever before - 39 million, or one in six Americans

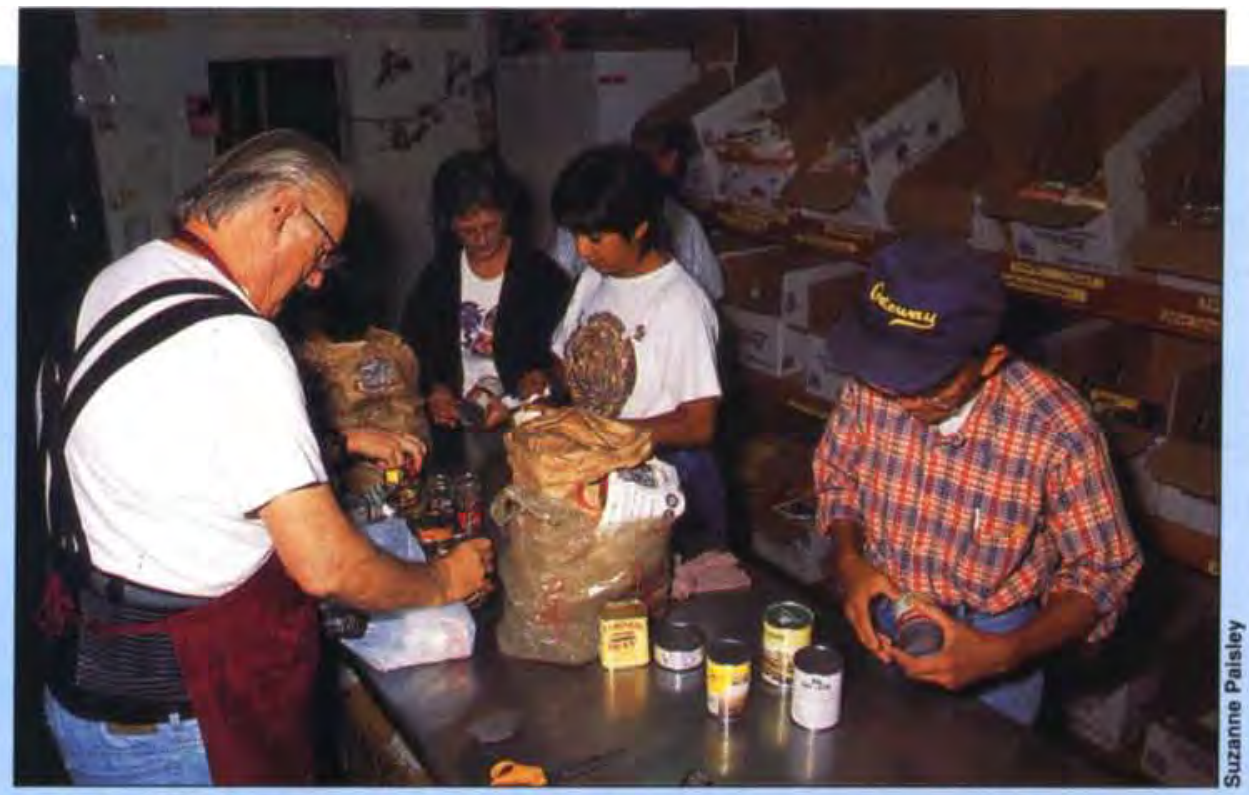

Federal assistance has not kept pace with the numbers of people requiring emergency food. Charities and religious organizations, when they can, shoulder an increasing amount of the need. Here volunteers in Contra Costa County inspect and sort donated food destined for free food baskets.

- the programs themselves are inadequately funded and the benefits they provide fall short of the need. These programs include the Food Stamp Program, the Special Supplemental Food Program for Women, Infants and Children (WIC), and the School Breakfast and School Lunch programs.

For instance, a statewide survey conducted by the California Community Childhood Hunger Identification Project (CCHIP) found that $39 \%$ of households receiving food stamps still experienced hunger, with monthly benefits lasting only 2 weeks. Contra Costa County figures show that emergency food recipients there receive an average of 50 cents per meal in food stamps.

CCHIP also found that food stamps are underutilized, with less than half $(48 \%)$ of those eligible actually receiving them. Reasons for not participating included lack of knowledge about the program, embarrassment, transportation difficulties and language problems.

Statewide, only $30 \%$ of eligible women, infants and children receive WIC benefits. The reasons are numerous. For one, WIC receives only twothirds of full funding. As a result, health departments change categories of eligibility and reduce outreach efforts. Of those who remain eligible, fewer are aware of relief programs.
Nevertheless, federal food programs are highly effective as far as they go. The General Accounting Office has calculated that every dollar spent on WIC prenatal care saves up to $\$ 4.21$ in Medicaid costs Inadequate funding of WIC means that nationwide nearly 3.5 million women and children are unable to participate.

The school lunch program is highly effective, with $98 \%$ of schools participating; for poor children this may be the only meal in the day. But other statewide figures show only $25 \%$ of eligible children receive school breakfasts, and $6 \%$ of eligible children receive summer food service. The reasons include administrative barriers, inadequate outreach and the stigma of participating.

Full funding of all existing federal food programs would cost an additional $\$ 10$ billion a year, less than $1 \%$ of total federal spending, and could eliminate hunger in this country by the year 2000, according to the Medford Declaration to End Hunger in the U.S., which was endorsed by more than 3,000 national leaders and organizations in 1991. - Editor

Material for this sidebar was derived from publications of Bread for the World, Tufts University, the General Accounting Office, the Contra Costa County Hunger Task Force and CCHIP. 